\title{
Do Fetichismo à Idade Positiva: apropriação territorial e política indígena no Rio Grande do Sul da Primeira República (1889-1925) ${ }^{1}$
}

Marcio Antônio Both da Silva*

Resumo: Os primeiros anos do século XX são marcados pela presença de uma preocupação por parte das autoridades governamentais do Brasil no que diz respeito à questão indígena. Um dos principais exemplos disso foi a criação, em 1910, de uma instituição federal responsável por tratar do assunto: o Serviço de Proteção ao Índio e Localização do Trabalhador Nacional (SPILTN). Essa atenção dirigida às populações indígenas também é visível no Rio Grande do Sul, estado onde o gerenciamento da matéria ficou a cargo da Diretoria de Terras e Colonização (DTC). Por seu turno, nesse caso em específico, juntamente com a implementação de políticas estatais voltadas à tutela dos indígenas, as áreas tradicionalmente habitadas pelas populações nativas foram alvo de um intenso processo de povoamento realizado especialmente por imigrantes europeus e seus descendentes. Assim, o interesse deste artigo é discutir a relação entre o gerenciamento da questão indígena levada a cabo por parte dos governos republicanos e o processo de ocupação territorial que marcou a região de matas do estado durante a Primeira República.

Palavras-chave: Índios. Terra. Estado.

* Doutor em História pela UFF. Professor do Curso de Pós-Graduação em História e do Colegiado de História da UNIOESTE/PR. Endereço: Rua 12 de Outubro, 926 - Centro. Marechal Cândido Rondon/Paraná - CEP 85960-000. E-mail: marcioboth@gmail.com 
Do fetichismo à idade positiva...

\section{Introdução}

Nos últimos anos, o período da Primeira República (18891930) vem recebendo atenção importante por parte da produção historiográfica brasileira ${ }^{2}$. No caso do Rio Grande do Sul, que será objeto específico deste artigo, a execução de análises sobre os primeiros 40 anos da República também tem encontrado receptividade positiva entre os pesquisadores, sendo que um exemplo disso é a recente publicação do livro Capitulos de bistória do Rio Grande do Sul (GRIJÓ et al., 2004). Embora o motivo dessa obra não seja especificamente o contexto da Primeira República, alguns de seus capítulos têm como objeto de reflexão questões relativas ao período. Da mesma forma, o livro Breve inventários de temas do sul, organizado por Francisco Roberto Targa (1998), também traz textos que têm como tema central de discussão o Rio Grande do Sul no contexto da Primeira República.

Além dessas coletâneas, igualmente temos a produção de textos específicos sobre questões variadas, como o livro $O$ aviador e o carroceiro, de René Gertz (2002), que trata das vinculações entre etnia, religião e política no Rio Grande do Sul do início do século XX. A recém-defendida dissertação de mestrado de Carlos Torcato (2011), que aborda a repressão ao jogo do bicho em Porto Alegre entre os anos de 1885 e 1917, e a de Miguel Stédile (2011), que versa sobre os clubes de futebol operário de Porto Alegre na primeira metade do século XX, também são expressões das novas abordagens mencionadas. Da mesma maneira, novas análises sobre o cenário político do Rio Grande do Sul desse período vêm sendo produzidas e, nesse sentido, destaca-se a tese de doutorado de Luiz Alberto Grijó (1998 e 2005) sobre a Faculdade de Direito de Porto Alegre e o ensino jurídico no Brasil, bem como sua dissertação de mestrado sobre a geração política de 1907.

Além dessa produção, temos a execução de pesquisas que têm como ponto de partida a questão agrária no Rio Grande do Sul da Primeira República, especialmente temas relativos ao povoamento e à colonização da parte norte do estado. Exemplos dessa produção são as pesquisas de Paulo Zarth (1997), Ludes Ardenghi (2003), José Nascimento (2007) e Ironita Machado (2009). Da mesma forma, 
a questão indígena no Rio Grande do Sul da Primeira República também é assunto de novas discussões e, nesse caso, destacam-se a produção intelectual de Breno Sponchiado (2000), Paulo Ricardo Pezat (2003), Joel João Carini (2005), Cintia Régia Rodrigues (2007), Soraia Sales Dornelles (2011), entre outros.

Conforme foi mencionado no início, a produção nacional sobre o período também foi alvo de avanços nos últimos anos. Destacase a reedição do conjunto de livros que compõem a História Geral da Civilização Brasileira (2006), sendo que alguns tomos dessa obra dedicam-se especificamente a tratar da questão. Do mesmo modo, temos a recém-lançada coletânea $O$ Brasil Republicano, organizada por Jorge Ferreira e Lucília de Almeida Delgado (2003), que, em certo sentido, veio para atualizar as discussões presentes no História Geral. Ademais, estudos sobre questões mais específicas vêm sendo produzidos ao longo das últimas décadas. Assim, trabalhos como os de Lilia Moritz Schwarcz (1993), Márcia Naxara (1998), Nísia Trindade (1999), Ângela Alonso (2002), Clodoaldo Bueno (2003), João Maia (2008), para citar alguns, são exemplos dessa renovação.

Essa nova produção, somada à já consagrada historiografia sobre a Primeira República ${ }^{3}$, compõe o arcabouço bibliográfico que serve de referência atual para pensar o período. Todavia, mesmo diante dessa considerável produção intelectual, as discussões a respeito da Primeira República estão longe de ser enceradas, e a história indígena, nesse sentido, ainda não recebeu atenção proporcional à sua importância. Por sua vez, mesmo nessa área, alguns avanços vêm ocorrendo e isso é comprovado pela recente publicação do livro $O s$ indios na história do Brasil, de autoria de Regina Celestino de Almeida (2010). Não só, mas englobando diferentes períodos da história, a publicação de um dossiê da Revista Anos $90^{4}$ sobre história indígena na América, a formação de grupos de trabalho ${ }^{5}$ organizados em torno da temática que promovem encontros de discussão em eventos nacionais e regionais promovidos pela Associação Nacional de História (ANPUH) demonstram a importância da temática indígena e a atenção que ela vem recebendo ultimamente.

Assim, nas linhas que seguem - iluminado pelas considerações produzidas nas pesquisas citadas - buscarei problematizar as peculiaridades do Rio Grande do Sul no que tange à elaboração de uma 
política indigenista durante as primeiras décadas da República. Tratarei, na medida do possível e dentro dos parâmetros de um artigo, das vinculações entre o projeto governamental de incorporação dos grupos indígenas característico do Rio Grande do Sul com processos mais amplos ligados à situação que o Brasil experimentava naquela quadra histórica. De modo particular, procurarei analisar a singular conexão entre a questão indígena e o processo de apropriação territorial ocorrido na parte norte do estado - espaço territorial tradicionalmente conhecido como região de matas -, durante os anos que se estendem entre 1889 e 1925.

Em termos metodológicos, a análise será estruturada a partir da investigação de dados referentes à política indígena rio-grandense presentes nos relatórios da Diretoria de Terras e Colonização (DTC), que à época era a principal instituição do Estado a lidar com o processo de apropriação territorial e, mais detidamente, com o gerenciamento dos assuntos relativos às populações indígenas que viviam no estado. Da mesma maneira, farei uso de informações presentes em descrições produzidas sobre a região alvo de análise. Os dados coletados em Processos Crimes movidos nas Comarcas dos municípios onde se localizavam as reservas indígenas existentes no Rio Grande do Sul também compõem parte do arcabouço de fontes que aqui serão analisadas. Esse conjunto de informações será contraposto à bibliografia produzida sobre a questão, sendo que o objetivo principal será perceber e demonstrar o quanto o processo de apropriação territorial está intimamente conectado à construção do problema indígena no Rio Grande do Sul do primeiro período republicano.

\section{Questão indígena e apropriação territorial no Rio Grande do Sul da Primeira República}

Os bugres desta província faziam parte dos Goytacases, que tendo sido expulsos por seus inimigos naturais, os Guaranis, aliados aos portugueses, se refugiaram para as matas, do 
interior do continente no princípio do século XVII, onde eram conhecidos pela denominação de Bororernos, Coroados e Bugres do Sul. Em meados, mais ou menos do século passado, estes últimos penetraram nesta província, ocupando toda a serra do Alto Uruguai, até o Ijuí Grande.

Faziam (os coroados) contínuas emboscadas aos Guaranis, e quando estes aprisionavam algum daqueles, vendiam-no como escravo, e desse fato é que se origina o vocábulo Bugre - que quer dizer escravo (CASTRO, 1887, p. 45).

Em 1872, uma extensão significativa das terras situadas ao norte do estado do Rio Grande do Sul estava administrativamente dividida entre quatro grandes municípios: Cruz Alta, Passo Fundo, Santo Ângelo e Vacaria. Eram nessas terras também que se localizava a maior parte das populações indígenas que viviam no estado. Segundo os dados do Censo de 1872, a população total das Paróquias que formavam essas municipalidades somava o montante de 59.589 pessoas (FEE, 1981, p. 81-83). No censo, não há registros sobre a quantidade de índios que ali viviam, mas segundo consta na Notícia descritiva da região missioneira, escrito em 1887, por Evaristo de Afonso Castro (português radicado em Cruz Alta, onde exercia a função de promotor público), o número de indígenas que habitavam aquelas terras era de 909 pessoas (CASTRO, 1887, p. 274). Em 1920, de acordo com os dados do Censo realizado nesse ano, o número de habitantes vivendo naquele espaço subiu para 276.270 indivíduos (FEE, Idem, p. 127-128), sendo que, entre 1872 e 1920, algumas novas municipalidades haviam sido criadas a partir da divisão dos quatro municípios inicialmente citados ${ }^{6}$.

Os dois Censos não trazem informações sobre a quantidade de índios que viviam na região. Contudo, segundo levantamento realizado por Cintia Régia Rodrigues (2007, p. 127), em sua tese de doutorado, em 1920, o Rio Grande do Sul possuía uma população indígena de 2.534 pessoas. A maioria dessa população estava localizada, conforme informações do relatório da DTC de 1910, nas 12 reservas indígenas demarcadas no estado, as quais se situavam nos municípios de Palmeira das Missões, Passo Fundo e Lagoa Vermelha (GONÇALVES, 1910, p. 155).

Anos 90, Porto Alegre, v. 18, n. 34, p. 305-337, dez. 2011 
Os números apresentados demonstram um aumento considerável da densidade demográfica na região no período entre os dois Censos citados. Tal fenômeno decorre principalmente do maior volume na entrada de imigrantes europeus e da migração de descendentes de imigrantes que provinham, em sua maioria, das colônias velhas fundadas no estado durante o século XIX (SILVA, 2009). Não somente isso, mas as fontes também indicam que havia uma intensa movimentação de populações provindas de outras regiões do Rio Grande do Sul e mesmo de outros estados do Brasil em direção à região (SILVEIRA, 1979, p. 265). Uma das consequências desse aumento demográfico foi a valorização do preço das terras, tanto é que Hemetério Velloso da Silveira (importante liderança política em Cruz Alta no período), em 1909, escrevia que devido à colonização com imigrantes: "[...] é surpreendente o modo por que o solo missioneiro, que há 48 anos, encontramos na maior parte desvalorizado, ou constando ainda de prédios rústicos baratíssimos, hoje, ninguém os adquire, senão por bem alto preço" (Idem, 1979, p. 145).

As informações fornecidas por Silveira, quando aproximadas dos números dos Censos de 1872 e 1920, ajudam a visualizar o quanto o povoamento foi responsável por dar maior valor de mercado às terras da região. Fator que está diretamente vinculado à constituição da questão indígena no Rio Grande do Sul. Todavia, para compreender esse processo em toda sua amplitude, é preciso ter em conta outras questões, sendo que dentre elas se destaca a forma como, ao longo da história do Brasil, os grupos indígenas estabeleceram suas relações e seus contatos com a "sociedade ocidental".

Assim, desde a chegada dos colonizadores portugueses ao Brasil e o processo de conquista do território e dos povos que aqui viviam que lhe é peculiar, até os dias atuais, as sociedades indígenas vêm participando das mais variadas formas na constituição daquilo que genericamente denominamos de "sociedade brasileira". Esta, por seu turno, é resultado de um longo processo que envolve questões variadas, como a formação de um Estado nacional. Porém um dos seus principais traços é o esforço realizado ao longo dos anos, especialmente por parte da elite política e econômica nacional, na perspectiva de definir e, ao mesmo tempo, estabelecer uma determinada "identidade nacional brasileira" que, ao fim e ao cabo, nos 
termos de Hobsbawm e Ranger (1984), não passa de uma tradição inventada. Desse modo, no processo de invenção do Brasil, ou melhor, de uma almejada identidade brasileira, homogênea e livre de conflitos sociais, bem como do povo portador de tal identidade, as sociedades indígenas vêm, desde o período colonial até os dias de hoje, ocupando lugares diferenciados nas representações elaboradas a respeito desse povo e dessa identidade.

Em termos históricos, tais diferenças são verificáveis no modo como a questão indígena foi legislada, abordada e inventada desde o período colonial até o republicano. Assim, se na colônia, como mostra Beatriz Perone (1992), a questão da liberdade e da utilização da mão de obra dos índios foi o foco que ocupou a preocupação das principais forças políticas da época. No período imperial, conforme Manuela Carneiro da Cunha (1992), a questão indígena deixou de ser "[...] essencialmente uma questão de mão de obra para se tornar uma questão de terras". Já com o fim do regime monárquico e a proclamação da República, alguns aspectos presentes nas legislações dos períodos anteriores incrementaram-se e outros são deixados de lado.

O diferencial da República foi a criação, em 1910, de um aparelho de Estado responsável por pensar e lidar especificamente com a questão indígena: o Serviço de Proteção ao Índio e Localização dos Trabalhadores Nacionais (SPILTN) que, a partir de 1918, passou a ser Serviço de Proteção ao Índio (SPI). Contudo, o novo da instituição não significava que os conteúdos que lhe fundamentavam eram totalmente desvinculados de experiências anteriores, pois questões de longa data discutidas continuaram coordenando e definindo o papel do SPILTN. Nesse sentido, a terra e a ocupação do território, o índio e o seu grau de civilidade, a produção e a possibilidade de transformar o índio em um trabalhador pacífico foram, de maneira geral, os pontos que definiram a ação do SPILTN e do SPI ao longo de suas existências.

Ademais, como demonstra Antônio Carlos de Souza Lima (1992, p. 161), um dos principais motivos que esteve na base da criação do SPILTN era o "[...] conhecimento-apossamento dos espaços grafados como desconhecidos nos mapas da época”, bem como o interesse em realizar a "transformação do índio em trabalhador nacional". Objetivos que eram estratégicos e inseriam-se num 
processo geopolítico, cujo ponto de convergência é a constituição do antes referido Estado nacional, bem como do contingente de trabalhadores necessário para realizar o "progresso" e a "consolidação" da nação, como apregoava e desejava a elite político-econômica brasileira do início do século XX.

Em linhas gerais, o SPILTN foi fruto da expansão do Estado nacional e, como agência de Estado, tinha poder para arbitrar sobre "os limites de intervenção do Estado sobre a sociedade civil" e, nas palavras de Antônio Carlos de Souza Lima (1987), definir o modo como tal poder era exercido era um "dos grandes temas do período”. Enquanto instituição, ele era regido e organizado dentro dos quadros do Ministério da Agricultura Indústria e Comércio (MAIC) e estava diretamente relacionado aos debates relativos à intervenção do Estado em zonas de fronteira que, a seu turno, são anteriores à constituição do Ministério. Como parte do MAIC, concordando com Sônia Mendonça (1997), o SPILTN estava nacionalmente sob a égide de uma posição então dominada no campo político, contudo dominante no que dizia respeito à política indigenista (LIMA, 1995). Fato que deve ser levado em conta para melhor compreender os conflitos e as disputas que marcaram sua criação, bem como a atuação do SPILTN e o que se conta dessa instituição nos dias de hoje.

Outra questão importante relativamente a esse assunto é a de que a fundação de uma agência de Estado, responsável por lidar com o problema indígena na Primeira República, resultou na elaboração de interpretações históricas que definem o período como a idade de ouro das políticas indígenas no país (LIMA, 1987). Representação esta que atuou muito no sentido de ocultar os conflitos que são peculiares e acompanharam o processo de constituição do SPILTN. Tanto é que, no caso do Rio Grande do Sul, parte da produção historiográfica que trata da questão ainda está muito pautada nessa ideia e, além disso, outro traço peculiar é a insistência de alguns estudiosos em destacar o Rio Grande do Sul como estado "pioneiro" e "autônomo" frente à Federação no que tange ao trato com os índios.

Assim, tanto pesquisas acadêmicas ${ }^{7}$ quanto artigos publicados em jornais de divulgação regional (SIMONIAN, 1979) tomam a constituição do SPILTN como o grande momento da legislação 
indígena e sublinham que, antes da instituição dessa agência nacional, o Rio Grande do Sul já vinha atuando entre os povos indígenas, sendo que, mesmo após sua fundação, o SPILTN exerceu pouca influência no território rio-grandense. Dessa forma, a afirmação de que "[...] o governo positivista do Rio Grande do Sul, mesmo antes da criação do SPI, mostrava preocupação com a questão indígena e propôs-se a implantar uma proposta de política indigenista" (CARINI, 2005, p. 134) é bastante corriqueira na bibliografia que trata do tema.

$\mathrm{Na}$ verdade, tal ponto de vista não está de todo errado, pois efetivamente as fontes trazem referências a certa preocupação por parte dos agentes governamentais, especialmente aqueles ligados à DTC, em lidar com a questão indígena. Contudo, pouco se tem feito no sentido de contrapor tais "preocupações" com o próprio processo de constituição da questão indígena no Rio Grande do Sul e no Brasil. Problema que, conforme já foi ressaltado, está muito diretamente ligado ao processo de apropriação territorial, visto que as reservas indígenas do estado estavam todas situadas em uma região que conheceu um intensivo processo de colonização e povoamento no período. Em outros termos, é muito perigoso - ingênuo até aceitar sem grandes questionamentos o lugar de vanguarda do Rio Grande do Sul em relação ao problema indígena.

Nesse sentido, é importante pontuar que os agentes responsáveis por administrar a questão indígena no estado que estavam agrupados na DTC eram parte ativa do governo. Da mesma forma, a teoria que fundamentava suas ações - uma leitura particular do positivismo de Auguste $\mathrm{Comte}^{8}$-, como é possível verificar na documentação oficial da época, igualmente era empregada para justificar os mais diferentes projetos governamentais. Logo, é necessário que se faça a devida crítica das informações presentes nas fontes e a sua contextualização ao momento em que foram produzidas, bem como que sejam identificados os grupos que estavam envolvidos na sua produção. Ademais, em termos das políticas indigenistas, essa suposta vanguarda não torna o Rio Grande do Sul e seus governantes melhores e movidos por ímpetos mais humanitários do que qualquer outro estado da Federação como geralmente se pretende fazer entender em afirmações como a que segue:

Anos 90, Porto Alegre, v. 18, n. 34, p. 305-337, dez. 2011 
[...] os adeptos gaúchos de Comte - iluminados pelos demais confrades, diretores da Igreja Positivista Brasileira e, sobretudo Rondon - lançaram mão da oferta ou oportunidade que lhes surgia, na intenção de colocar em práticas ideias em que convictamente acreditavam, emanadas do ideário de Augusto Comte. Fizeram o que era possível, dentro dos limites impostos, tanto pelo governo, como pela mentalidade que seguiam (SPONCHIADO, 2000, p. 86).

Ao tratar os "adeptos gaúchos de Comte" como "[...] homens que fizeram o possível”, dentro do permitido pelo Governo e pela teoria que seguiam, Sponchiado quase retira tais personagens do momento histórico que eles vivenciavam e prende-os dentro de uma redoma, cujo nome é "positivismo". Portanto, pouco ajuda na compreensão do processo em toda sua complexidade, pois, entre outras coisas, não percebe a importância dos próprios índios em suas ações e mobilizações no sentido de definir a questão indígena no estado.

Evidentemente que os méritos do SPILTN e da própria DTC no que diz respeito ao reconhecimento da importância da questão indígena não devem ser negados. O problema está em analisar tais instituições de forma isolada retirando-as do mundo social onde foram criadas e funcionavam. Em outras palavras, o estabelecimento dessa separação dificulta perceber a eficácia e os sucessos que essas instituições obtiveram em algumas de suas tentativas de incorporação e modificação dos modos de vida tradicionais de alguns povos nativos e que o resultado dessas práticas pouco deu conta de realizar os ideais humanitários que teoricamente lhes fundamentavam.

Outro ponto que as interpretações centradas na ideia de espaco sagrado obscurecem é o das disputas relativas ao modo como a discutida instituição responsável pela proteção aos indígenas deveria funcionar, quais seriam seus objetivos e a maneira mais apropriada de ação. No geral, tais textos tomam o SPILTN como resultado de discussão travada entre o diretor do Museu Paulista, Hermann von Ihering, e os positivistas aglutinados em torno da Igreja Positivista do Brasil, Teixeira Mendes e Miguel Lemos. O primeiro supostamente defendendo o extermínio dos indígenas em detrimento dos imigrantes; os dois últimos favoráveis à incorporação dos grupos fetichistas à sociedade. 
Todavia, as diferentes perspectivas adotadas pelos positivistas e pelo Diretor do Museu Paulista representam apenas uma face do processo. Antônio Carlos de Souza Lima (1987) demonstra que, além dessas duas propostas, existiam diferentes projetos sobre a forma como a questão indígena deveria ser administrada. Assim, os motivos que levaram o SPILTN a ser estruturado a partir das propostas veiculadas pelos positivistas longe de ser uma "decisão humanitária” dos grupos que administravam o Estado, estava vinculada a uma opção estratégica realizada pelo governo. Ou seja, como os problemas discutidos à época giravam em torno da necessidade de incorporação dos povos indígenas. Já que se objetivava à expansão do território nacional, à proteção da fronteira, dos espaços conquistados pelo avanço das populações em direção a esses territórios e à elaboração de uma identidade nacional a partir do anulamento das diferenças, coube ao SPILTN realizar parte da tarefa. Restava, portanto, decidir entre as propostas de ação existentes qual a que mais propriamente daria conta do objetivo.

Por seu turno, o Exército, onde aglutinavam-se os principais representantes do positivismo do país, era a principal instituição preocupada em demarcar as fronteiras territoriais e simbólicas da nação, bem como definir uma identidade nacional (CARVALHO, 2005; CASTRO, 1995). O militar Candido Rondon, na época, atuava em regiões de fronteira na instalação de linhas telegráficas e em seus trabalhos vinha mantendo contato com as populações indígenas (BIGIO, 2003). Fato que lhe garantia um conhecimento específico a respeito dos indígenas, assim como das regiões por eles habitadas. Além disso, ele era um engenheiro-militar, portanto, o exemplo maior do "soldado-cidadão": representação que, no período, simbolizava um indivíduo especial a quem caberia o papel maior na "missão civilizadora" então em curso (MAIA, 2008).

Tudo somado, nada mais prático do que, entre as possibilidades existentes, optar pela que parecia mais viável, bem como autorizada socialmente e convidar Rondon para ser o principal organizador do SPILTN'. Em outras palavras, o que define a estruturação dessa agência nos moldes como ela foi elaborada são antes motivos estratégicos e políticos do que humanitários: afinal, gerir um Serviço que seria quase sempre deficitário, em termos de receita e suporte, “[...] 
num ministério (MAIC) igualmente secundário parece ter sido em grande medida uma tarefa cênica, para a qual os positivistas estavam especialmente preparados" (LIMA, 1995, p. 116).

No Rio Grande do Sul, na maior parte do período, a tarefa de administrar a questão indígena ficou sob responsabilidade da D'TC, instituição que tinha à sua frente Carlos Torres Gonçalves que, assim como Rondon, era um adepto convicto do positivismo religioso (PEZAT, 1997). Desse modo, a influência positivista foi dominante e a preocupação central da DTC, como fica claro nos relatórios, foi a da incorporação dos povos indígenas, sua transformação em agricultores produtivos e a sua paulatina passagem do período fetichista à idade positiva.

De acordo com a teoria positivista formulada no século XIX por Auguste Comte, a humanidade em sua evolução passa por diferentes estágios de desenvolvimento: o teológico, o metafísico e o positivo. O estágio teológico é dividido em outros três: o fetichista, o politeísta e o monoteísta. Os índios, segundo essa teoria, encontravam-se no primeiro estágio do desenvolvimento humano, no qual " [...] o homem é a medida de tudo atribuindo aos acontecimentos os mesmos impulsos que o guiam na luta pela sobrevivência” (Idem, p. 59). Dessa forma, simplificando a teoria de Comte e sua interpretação aqui no Brasil, por serem fetichistas, os índios teriam maior facilidade para alcançar o estado positivo, exatamente porque não haviam passado e sido contaminados pelos problemas característicos do período metafísico.

No Rio Grande do Sul, a atuação do SPILTN entre os indígenas é reconhecidamente menor do que em outros estados da Federação. Tal situação foi resultado da maneira como os índios eram classificados pelo Serviço de Proteção, e o critério que regulava a classificação era o grau de sua incorporação na sociedade nacional, sendo prioridade agir entre os grupos mais resistentes (LIMA, 1997). As populações nativas que viviam no Rio Grande do Sul eram concebidas, na época, como participando de um processo de incorporação bem mais avançado do que os Xokleng de Santa Catarina, por exemplo. Situação que ajuda a compreender porque, em meados de 1911, foram reunidas em uma só as inspetorias do SPILTN dos dois estados e a sede instalada em Santa Catarina. 
Essa medida, portanto, longe de ser resultado da autonomia do Rio Grande do Sul em relação ao governo central como querem alguns intérpretes e como indicam algumas fontes, foi consequência direta da falta de recursos disponíveis ao SPILTN. Diante disso, seus quadros necessariamente precisavam optar por agir mais diretamente em espaços onde os conflitos entre indígenas e ocidentais eram mais fortes. Quanto ao grau de "incorporação" a que estavam submetidos os indígenas que viviam no Rio Grande do Sul, o relatório da DTC de 1910 traz uma descrição esclarecedora:

[...] pelos contatos em que se acham [os índios] há muitos anos com os ocidentais, poucos hábitos e costumes da vida primitiva conservam. Perderam a sua indústria, talvez por encontrarem nos ocidentais o equivalente dela [...]. Desconhecem a medicina dos antepassados. Não guardam sequer lembrança das suas tradições. E o único traço de nacionalidade que conservam vivaz, aliás o mais característico, é a linguagem. Os homens conhecem quase todos o português; as mulheres, porém, raramente e pouco (GONÇALVES, 1910, p. 152).

Segundo consta nos relatórios produzidos por Gonçalves, diante da realidade a que estavam submetidos os índios do Rio Grande do Sul, a principal tarefa da DTC deveria ser realizar os serviços relativos à demarcação das suas terras. Todavia, as ações da diretoria não se resumiam a isso, mas buscava-se também a execução de projetos que teoricamente deveriam ajudar no processo de incorporação dos grupos fetichistas. Em 1910, por exemplo, Torres Gonçalves propõe um conjunto de medidas a fim de "levantar o moral" dos índios e torná-los mais "úteis socialmente". Dentre elas, destacam-se o fornecimento de vestuário e ferramentas agrícolas; alguns animais, cavalares e bovinos; gaitas de foles para aproveitar as aptidões musicais dos índios; carpinteiros que os auxiliassem na construção de habitações; uniformes militares aos caciques e seus ajudantes, buscando aumentar a convergência entre eles e desenvolver o espírito de subordinação dos inferiores para com os superiores.

Outro traço característico da política indigenista rio-grandense era o caráter leigo dado à proteção. No conjunto dos relatórios, é 
possível verificar a existência de um esforço por parte dos agentes da DTC para que a igreja não interviesse no processo e, os responsáveis pela "tutela" eram proibidos da prática do ensino religioso entre os nativos. Aqui é interessante abrir um pequeno parênteses e registrar que a determinação de proibir o ensino religioso entre os indígenas estava atrelada à leitura da teoria positivista, uma vez que, segundo os ensinamentos de Comte, a religião era o principal aspecto a caracterizar o período metafísico da evolução humana. Assim, era muito importante que os grupos indígenas não entrassem em contato com os traços que caracterizavam esse momento histórico - especialmente o cristianismo -, já que isso resultaria em mais um obstáculo a ser enfrentado no processo de evolução para o estado positivo. Contudo, é importante grifar que, mesmo diante dessas exigências, a presença e a atuação das Igrejas entre os grupos indígenas no período foram significativas ${ }^{10}$.

No conjunto de propostas feitas pelo diretor da DTC, congregam-se de forma nítida as ações características do SPILTN. Movidos pelo objetivo de incorporação, os Agentes do Serviço buscavam incentivar os índios a adotarem costumes comuns aos "civilizados". Assim, pretendiam torná-los dependentes das "benesses da civilização", e tal dependência, por seu turno, responsabilizar-se-ia por fazer com que os índios "por si mesmos" passassem a fazer esforços no sentido de suprimi-la. Nessa perspectiva, um dos principais pontos que o SPILTN e a DTC buscavam combater era o nomadismo característico dos grupos indígenas, pois

[...] pôr-lhe um fim era destituir de vez o nativo de uma vivência cultural e politicamente diferenciada do espaço geográfico (uma territorialidade específica), obrigando-o ao reconhecimento de um território alheio e imposto de fora. Este processo tem sua explicação nas preocupações simultâneas: a) circunscrever porções de terra para localizar e fixar populações nativas, inserindo-as no estoque fundiário disponível sob controle estatizado, e b) liberar o espaço em torno para a empresa privada (LIMA, 1995, p. 197).

A execução desse objetivo exigia a realização de uma mudança profunda na noção de território comum aos grupos indígenas. 
Entretanto, isso não fica evidente nas fontes, pois a narrativa dominante é a de que, por serem diferentes dos "ocidentais", principalmente por serem considerados como crianças, os índios deveriam ser tratados de forma diferenciada. No relatório de 1910, por exemplo, Gonçalves descreve o caso da prisão de seis índios do Toldo ${ }^{11}$ de Rio Carreteiro, situado no município de Passo Fundo, porque haviam matado "dois brasileiros ocidentais". O que levou ao crime foi o fato de esses brasileiros terem anteriormente assassinado dois índios. Para Torres Gonçalves, perante a moral e os costumes dos seus pares, os índios não eram criminosos, já que, "por serem índios" haviam cumprido seu dever de vingar a morte de seus irmãos. Em consequência, ponderava, "[...] não é sábio nem justo pretendermos resolver casos passados com fetichistas, servindo-nos para isso de um código criminal feito para ocidentais" (GONÇALVES, 1910, p. 152). Por sua vez, a mesma reflexão não encontrava espaço quando a questão em pauta era a terra, pois, cabe perguntar: até que ponto é justo impor uma noção de território construída por ocidentais a grupos "fetichistas" que não conheciam a noção de propriedade privada da terra ou que recentemente, em alguns casos, vinham entrando em contato com esse conceito e sua prática?

Quando a questão da terra é observada a partir da situação local, isto é, da realidade experimentada pelos indígenas nas áreas onde eles residiam, fica nítido que o problema era bem mais complexo do que a narrativa dominante nas fontes oficiais dá a entender. Entre outras coisas, fica evidente que o respeito à "moral indígena" era mais um argumento de que uma prática propriamente dita. Em 1911, por exemplo, Carlos Torres Gonçalves acusa, que no Toldo de Nonoai - situado no município de Palmeira das Missões -, os "civilizados" convivem muito próximos e arrendam as terras indígenas "[...] por uma ninharia, além do que o arrendamento é pago em mercadorias, vendidas por preços excessivos" (GONÇALVES, 1911, p. 155-156). Nesse toldo, as relações dos indígenas com as autoridades locais são descritas como conflituosas, pois os índios tinham-nas "[...] em conta de seus perseguidores e espoliadores, e isso porque em qualquer dúvida ou qualquer questão surgida entre eles e os brasileiros, sobre pretextos fúteis, são sempre sacrificados" (Idem, ibidem). As terras do Toldo de Serrinha, em Passo Fundo, 
também eram arrendadas para um tal Manuel Bento Souza e, segundo Torres Gonçalves, “[...] os índios não tinham toldo organizado, viviam espalhados pelos campos e matos. Atualmente, a população é reduzida a cerca de 150 habitantes, devido às perseguições sofridas, especialmente daquele arrendatário, até pouco tempo ainda subdelegado de polícia" (Idem).

A descrição demonstra a distância existente entre os discursos de proteção, as supostas razões humanitárias que lhe fundamentavam e o que realmente se dava no contexto local. Em outros termos, o arrendatário Manuel Bento era parte do conjunto de pessoas que, na região, representavam o Estado, visto que era subdelegado de polícia. Informação que ganha sentido quando levamos em conta que para um indivíduo exercer esse cargo, precisaria fazer parte de um conjunto complexo de relações, uma vez que, de acordo com as disposições da Constituição estadual, o subdelegado deveria ser nomeado pelo Intendente, o qual, na maioria das vezes, era representante do Presidente do Estado e líder municipal do Partido Republicano Rio-grandense ${ }^{12}$. Nessa perspectiva, um ponto que convém sublinhar é que, entre as propostas e projetos formulados nas instituições centrais e as práticas locais, havia um espaço a ser percorrido. Lacuna que, entre outras coisas, era preenchida pelo modo como a ocupação do território vinha se desenvolvendo, bem como do envolvimento, intencional ou não, dos índios no processo.

Exemplo disso aconteceu em 1926, no município de Palmeira das Missões: o fato está descrito em um Processo crime, ocorreu no distrito de Nonoai e resultou na morte de um índio, além de ferimentos em outros tantos. Consta na denúncia que José Joaquim de Moura (casado, brasileiro, com 53 anos de idade), subintendente de Nonoai, acompanhado de escolta formada de praças da polícia administrativa e de civis, no dia 24 de abril de 1926, armados de "revólveres, facas e relhos", foram "[...] a casa comercial de Miguel do Carmo Flores, onde se achavam pacatamente, na mais perfeita ordem, uns 20 índios fazendo compras" (PROCESSO CRIME $\mathrm{n}^{\circ}$ 254. Cartório Civil Crime. Município de Palmeira das Missões, 1926. Maço 12). O objetivo de José Moura era fazer com que os índios saíssem da cidade e, ao chegar à venda, "[...] a referida escolta entrou a espancar brutalmente o grupo de índios tirando-os para 
rua e levando-os por esta a fora, sempre debaixo dos maiores atos de crueldade" (Idem). Enquanto estava realizando a expulsão dos índios a escolta formada pelo subintendente de Nonoai foi abordada pelo capitão da Polícia Militar Antônio Pinto Ribeiro Deiró (com 53 anos de idade, viúvo, residente em Passo Fundo), que apoiado em uma força de seu comando, "[...] intimou o referido subintendente a fazer cessar tão lamentável cena, quando os pobres índios foram deixados em paz, sendo acompanhados pelo mesmo capitão Deiró até fora do povoado" (Idem). Diante dos fatos, o Promotor Público encerra a denúncia com a seguinte reflexão:

Destes atos de vandalismo, partidos de pessoas a quem a lei delegon o grande dever de zelar pela ordem e sossego do povo de Nonoai e tutelar indios indefesos resultou saírem feridos os índios João Lucidio, Sebastião Coió, Francisco Anastácio, Antônio Anastácio, Francisco Manuel, Joaquim Florentino e a índia Joaquina Frederico (Idem). (Grifos meus).

Conforme a testemunha de Dinarte Ayres de Toledo (30 anos, casado, deste estado, barbeiro, residente no município), o subintendente esteve em sua barbearia no dia do acontecido e, enquanto cortava o cabelo, "[...] referiu-se aos índios dizendo que a distração deles encerrava-se em beber e cantar" (Idem). Logo após, o subintendente saiu da barbearia, voltou um tempo depois acompanhado de escolta e seguiu em direção à venda de Miguel Flores. Segundo Toledo, na venda achavam-se uns 15 índios "[...] em completa ordem, e sem motivo algum, pois não houve discussão [...] foram espancados a pranchaços de espada, de facão e a relhaços" (Idem), fato que só cessou quando José Moura foi interceptado pelo capitão da Polícia Militar.

Em sua versão dos fatos, José Joaquim de Moura, afirma que a razão pela qual agiu daquela forma com os índios era porque um seu irmão de nome Marcírio e dois índios haviam brigado. Apesar de não ser a única justificativa, relaciona sua ação devido à grande quantidade de índios presentes na Vila e ao fato de que eles já estavam exaltados por causa da bebedeira, assim, "[...] achou mais conveniente retirá-los do povoado". No entanto, como os índios 
não obedeceram a seu pedido, pelo contrário "portaram-se incovenientes", tendo um deles, inclusive, dado-lhe "uma bofetada", viu-se obrigado a resistir, fazendo-os, pela força, saírem dali. Nesse momento, “[...] saiu pela frente o capitão Deiró, com uns 30 homens, armados a fuzil, o qual the intimou a que não mais fizesse aquilo com os índios, porquanto eles eram do governo" (Idem). Durante o Processo, são ouvidas 14 pessoas e, com exceção do subintendente, todas as versões são semelhantes à do barbeiro. Contudo, para dar maior eficácia à sua defesa, José Moura alega que a ação dos índios fora planejada por uns seus "inimigos políticos", cujo interesse era destituir-lhe do posto de subintendente.

Por algum motivo, difícil de ser conhecido devido às limitações da fonte, o Processo não chegou ao fim. Mesmo assim, ele é demonstrativo da situação vivida pelos índios na região. Os relatos presentes no Processo crime, por exemplo, possibilitam conhecer a confusão reinante sobre a quem caberia a tarefa de "regular" as ações dos indígenas, uma vez que, no conflito entre as duas forças policiais, o capitão da Polícia Militar deixa claro que os "[...] índios pertencem ao governo". Assim, para Deiró, caberia à Brigada Militar resolver as questões relativas aos índios e não a José Moura, que fazia parte da polícia administrativa. Portanto, deveria se preocupar apenas com assuntos de ordem municipal. No Processo crime, também fica nítida a forma como os índios eram percebidos pela população local, ou seja, na voz do subintendente, eles eram pessoas que encontravam distração em "beber e cantar"; na do barbeiro, eram "pessoas humildes e obedientes"; na do Promotor Público, eles são apresentados como indivíduos que deviam ser tutelados, pois eram indios indefesos. Ou seja, uma partilha plena das noções típicas, dominantes na época, sobre os indígenas (FERNANDES, 2007).

No fato acontecido em Palmeira das Missões, igualmente é possível visualizar a antes referida distância existente entre as políticas e os projetos de proteção e tutela com o que acontecia nos contatos estabelecidos entre as populações nativas e a sociedade ocidental. Nessa perspectiva, se aos integrantes da DTC e para os membros do SPILTN a incorporação era a meta principal de suas atividades, ela não encontrava eco entre as populações que viviam próximas aos Toldos. Isso é comprovado pelo fato de que a ação do subintendente 
foi expulsar os índios do povoado, ou seja, fica patente que existia um espaço definido para os indígenas, o qual não ficava dentro da Vila de Nonoai. Ademais, o Processo também indica que o conflito é um elemento indispensável para compreender tais contatos.

Em outras palavras, trata-se do encontro entre duas situações e culturas distintas, cuja marca é a competitividade, lembrando que o modo como a "sociedade nacional" se encontra com a "sociedade tribal" é variável e está proporcionalmente delimitada pelas diferenciações próprias, tanto dos grupos tribais como dos segmentos nacionais que entram em contato com os indígenas, pois "nem o contingente indígena, nem o contingente nacional apresentam aspectos unívocos" (OLIVEIRA, 1996, p. 177). Assim sendo, não se trata de relações entre "[...] entidades contrárias, simplesmente diferentes ou exóticas, umas em relação a outras; mas contraditórias, isto é, que a existência de uma tende a negar a outra” (Idem, p. 46) (Grifos do autor). Portanto, conforme Roberto Cardoso de Oliveira, uma relação de friç̧ão interétnica, cuja característica mais marcante é a expansão da sociedade brasileira sobre os territórios tribais, da qual o resultado histórico principal foi a "[...] destruição dos indígenas (depopulação, desorganização tribal, desagregação e dispersão das populações tribais, etc.)" (Idem, p. 47).

A partir desse ponto de vista, a grande meta da incorporação que movia a ação dos positivistas aglutinados em torno da DTC para o caso do Rio Grande do Sul ou do SPILTN para o caso nacional, não tem como acontecer de forma completa e total como queriam os Agentes do Serviço. Assim, é preciso levar em conta que as diferentes sociedades fazem leituras próprias dos processos sociais e dos contatos que estabelecem com outros grupos. O que significa que dificilmente rompem completamente com certos aspectos que caracterizam sua "cultura original", os quais continuam sendo importantes elementos de interpretação da sociedade, das mudanças de que estão participando e da situação que tais grupos vivem. Nesses termos, é importante grifar que a "[...] sobrevivência de algumas sociedades tribais, se bem que descaracterizadas, não é suficiente para esconder o sentido destruidor do contato" (Idem, ibidem). Ou seja, por mais "humanitários" que os contemporâneos da Primeira 
República pretendiam ser em seus projetos para as populações nativas, o resultado de sua ação foi altamente destruidor.

Destruição que encontra lugar de existência nos conflitos que marcaram os contatos entre "sociedade tribal" e "sociedade nacional" na história do Brasil. Lutas que aconteceram movidas, tanto pela questão da apropriação territorial como pelas concepções que esses grupos guardavam e guardam um a respeito do outro. Nesse sentido, o relatório da DTC de 1921 traz outro exemplo do quanto os contatos entre indígenas e ocidentais eram conflituosos. Nesse caso, Torres Gonçalves relata que, no Toldo do Ligeiro, em Passo Fundo, um italiano assassinou um índio "por simples perversidade". $\mathrm{O}$ assassino foi capturado e condenado. No relatório, não consta qual é especificamente a condenação, mas o motivo que, segundo o diretor da DTC, levava a se cometerem crimes contra os indígenas consistia em "[...] os ocidentais, especialmente os de origem estrangeira, considerarem ainda os silvícolas animais inferiores do que como seres humanos" (GONÇALVES, 1921, p. 463).

As críticas que o diretor da DTC realizava ao comportamento dos "ocidentais" foram utilizadas posteriormente para justificar o senso de humanidade dos agentes governamentais rio-grandenses da Primeira República em relação aos indígenas. Elas são facilmente localizáveis ao longo dos relatórios da DTC. Por sua vez, os descontentamentos de Torres Gonçalves em relação ao funcionamento da política indigenista são expressão de um ponto de vista que também estava permeado de vícios e problemas. Em 1914, por exemplo, o diretor da DTC tecia comentários ásperos a respeito do fato de não existirem verbas destinadas ao melhoramento dos serviços de proteção aos indígenas, enquanto a União gastava "milhares de contos com a introdução de imigrantes no país". No mesmo ano, por seu turno, ele também comemorava o início da execução e da organização, por parte do Governo Federal, de um centro agrícola voltado à atração e instrução de indígenas que passou a funcionar na área do Toldo do Rio Ligeiro, em Passo Fundo. Cabe sublinhar que a fundação desse centro agrícola é demonstrativa do esforço realizado no sentido de treinar os indígenas na prática de trabalhos considerados essenciais para sua evolução e para chegarem mais próximos à civilidade. Ademais, também é representativa do interesse 
na formação de trabalhadores treinados, definidos como necessários ao desenvolvimento do estado em específico e do país como um todo (NAXARA, 1998), ou seja, a tão apologizada "proteção fraterna aos fetichistas" era um meio para se chegar a um fim.

Outra medida executada pela DTC, cuja meta era apurar o processo de incorporação e proteção dos índios, bem como dar conta dos objetivos anteriormente expostos, foi a instalação no interior dos Toldos de "[...] um homem com família, tendo capacidade para dar aos indígenas educação compatível com a receptividade deles" (ALVES, 1917, p. XVI). Tais indivíduos, chamados de encarregados, seriam responsáveis por auxiliar os índios nas mais diferentes situações. Destaca-se, nessa perspectiva, a indicação de que eles deveriam ajudar os índios na construção de casas de madeira, cujo modelo seria fornecido pelas Comissões de Terras e Colonização (Ver figura 1).

\section{Figura 1 - Modelo de habitação para indígenas}

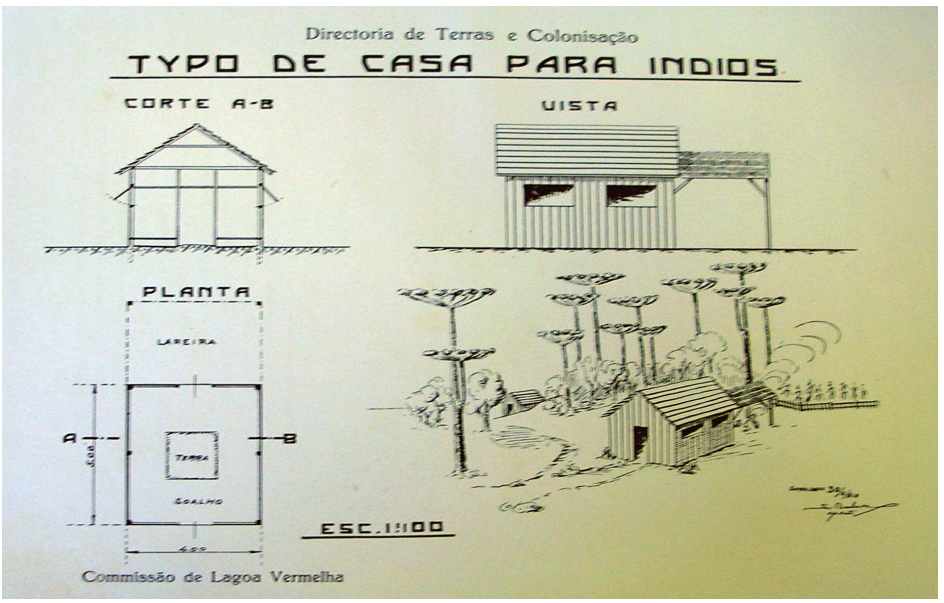

Fonte: (GONÇALVES, 1918, anexos).

Também era tarefa dos encarregados ajudar na construção de mobiliário, principalmente leitos, além de auxiliar os índios na execução de suas lavouras. Às suas esposas, caberia a tarefa de ensinar trabalhos caseiros às índias, especialmente os de costura e, enfim, era obrigação do encarregado proteger os indígenas de possíveis 
perseguições e explorações feitas pelos ocidentais. Com essa série de práticas, objetivava-se encaminhar, no mais curto prazo possível, os índios a poderem viver de seus próprios recursos e, sobretudo, respeitar e "fazer respeitar a sua organização própria e as suas crenças" (Idem). Interesses bastante antagônicos, uma vez que a sua realização, a partir do emprego dos métodos então utilizados, levava a alterações profundas no modo de vida e organização das populações nativas.

As políticas indigenistas formuladas e postas em prática pela DTC, conforme vem sendo aqui destacado, foram instrumentos utilizados na perspectiva de tornar a incorporação dos grupos nativos a referida "vida industrial moderna" mais eficaz e, portanto, carregam muito pouco dos valores humanitários que geralmente lhes são atribuídos. Ao fim e ao cabo, os Toldos seriam centros de formação, sendo que o encarregado e sua família teriam papel de preparar os índios para a sua incorporação definitiva. Coisa que não é peculiar à política indígena da Primeira República, pois, como demonstra Manuela Carneiro da Cunha, durante o século XIX, a prática de ampliar as necessidades dos índios e, ao mesmo tempo, restringir as possibilidades que eles tinham de satisfazê-las era política muito utilizada para sujeitá-los ao trabalho (CUNHA, Idem, op, cit.).

Outra questão importante e pouco discutida no quadro da produção bibliográfica sobre os índios no Rio Grande do Sul diz respeito ao modo como eles receberam as políticas governamentais voltadas à sua proteção. Os relatórios trazem informações sobre o problema, as quais, além de serem escassas, são manejadas pela pena do diretor da DTC. No relatório de 1918, por exemplo, Carlos Torres Gonçalves traz notícias de uma visita que fizera ao Toldo de Inhacorá, situado no município de Palmeira das Missões, e informa: a questão que os índios mais reclamavam era a da demarcação de suas terras. Em visita que fez ao Toldo de Guarita, também em Palmeira, o pedido repetia-se. Torres Gonçalves escreve que, ao insistir com o cacique do Toldo sobre seu interesse em outras coisas "[...] conforme nos haviam pedido alguns de seus índios, ele acrescentou firme: depois que o Governo demarcar nossas terras, então eu vou fazer uma reclamação de tudo que nós precisamos" (GONÇALVES, 1918, p. 311), (Grifos do autor). 
A fala do cacique, manejada por Torres Gonçalves, evidencia alguns pontos interessantes: 1) aos olhos do diretor da DTC, que estava falando para a sociedade e pensando ações governamentais, fica patente sua convicção sobre a necessidade da tutela e que ela é bem-vinda pelos próprios indígenas, pois, além de aceitarem, exigiam a demarcação de suas terras que era definida como o "fundamento de toda a proteção"; 2) para o cacique, que estava falando em nome dos índios, a partir de sua situação local e para um representante da sociedade envolvente, a ação do governo em demarcar suas terras também era apresentada como bem-vinda. No entanto, não necessariamente sua leitura era feita nos termos da tutela, visto que ter suas terras demarcadas, numa visão estratégica, embora significasse reconhecer o poder do Estado, daria novos contornos à relação dos índios com os ocidentais, principalmente no que diz respeito à disputa pelo território que ocupavam. A demarcação significava a abertura de um conjunto de preceitos que os indígenas poderiam manipular e, a partir deles, poderiam acionar o Estado no sentido de exigir o respeito pelas terras demarcadas. Pensar diferente equivale a concordar com os positivistas na sua convicção de que os índios não passavam de crianças, as quais deveriam ser tuteladas. Em outras palavras:

[...] a política indigenista não é mera aplicação de um projeto a uma massa indiferenciada de habitantes da terra. É, como toda política, um processo vivo formado por uma interação entre vários atores, inclusive indígenas, várias situações criadas por esta interação e um constante diálogo de valores culturais. A legislação que define, do mesmo modo, é muito mais do que o mero projeto de dominação mascarado em discussão jurídica, e merece ser olhada com outros olhos, para que dela se possa tirar toda a informação que ela pode nos fornecer (PERONE-MOISÉS, 1992, p. 129).

Assim, as políticas indigenistas formuladas no Rio Grande do Sul durante a Primeira República, que tradicionalmente são apresentadas como exemplo da alta preocupação e da vanguarda dos agentes governamentais, influenciados pelo positivismo, em relação aos povos fetichistas, deve ser problematizada. De acordo com o que 
foi frisado anteriormente, alguns pesquisadores que se propuseram a pensar a questão indígena no período, do meu ponto de vista, deram muito valor e, por vezes, exaltaram as políticas indígenas e seus respectivos preceitos positivistas sem fazer a devida relação do ideal com o possível. Em outras palavras, a teoria positivista que, em alguns casos, é muito bem explicitada, desde o ponto de vista histórico até o filosófico, acaba virando uma "camisa de força", a partir da qual os autores buscam perceber a sua ação na prática e não fazem um retorno da prática à teoria. Consequentemente ao fim dos textos, o leitor fica com a impressão: $e$ se não fosse o positivismo e os positivistas, o que seria dos indios? Contudo, conforme se buscou demonstrar ao longo dessas linhas, essa é uma opinião que deve ser mais detidamente estudada, uma vez que a constituição do problema indígena no contexto da Primeira República foi bem mais complexo do que a primeira vista demonstra ter sido.

\section{Considerações finais}

Mesmo diante da recente produção de pesquisas que tem como objeto de reflexão assuntos relativos à Primeira República, é importante frisar que ainda há muito a ser discutido sobre o período e o contexto. Volto a ressaltar que a temática da história indígena, tanto em termos de Rio Grande do Sul como de Brasil, necessita de novos olhares e mesmo de olhares renovados. Nessa perspectiva, é importante que tais análises sejam realizadas levando-se em conta o fato de que, quanto mais nos afastamos na história, mais difícil fica encontrar fontes que nos permitem trabalhar com a questão, uma vez que os documentos, em sua grande maioria, e, para alguns casos, em sua totalidade, são elaborados por agentes externos.

Nesses termos, como demonstra Alfredo Berno de Almeida (2008), é preciso ter cuidado quando nossas análises partem de fontes externas, especialmente as produzidas pelas diferentes instâncias do Estado, pois no interior delas está uma visão de mundo que, ao fim e ao cabo, tem a intensão de criar o mundo da qual elas tratam. Além disso, quando o tema em questão é o da história indígena, outro ponto importante a se destacar é o da vinculação entre o processo de 
apropriação territorial e a constituição da questão indígena no Brasil. A questão da terra, ou melhor, entender o modo como se constrói a questão agrária brasileira é fundamental para compreender o sentido e os significados dados aos contatos - marcados pelo conflito - estabelecidos entre sociedade tribale sociedade nacional na história do Brasil.

Assim, para voltar ao caso do Rio Grande do Sul, se em 1921, Torres Gonçalves escrevia que um dos motivos principais das violências cometidas contra os índios ligava-se ao fato de não lhes ser reputada, pelos ocidentais, a condição de seres humanos, e sim de "simples animais domésticos", isso não quer dizer que efetivamente as populações indígenas se enquadravam nessa visão. Em outras palavras, um dos objetivos dessa representação era justificar a política indigenista implementada pelo Estado na época. Consequentemente buscava suprimir possíveis conflitos de interpretação e prática, logo, dava legitimidade à noção dominante de que era tarefa do Estado proteger o índio, demarcar-lhe as terras, construir-lhe casas, levá-lo sem alterações bruscas e, a partir de sua própria vontade, pensavam os positivistas, do fetichismo ao estado positivo.

De maneira geral, esse objetivo teórico dos positivistas foi perseguido e fundamentado na ideia de uma "ação humanitária para com nossos irmãos fetichistas". Entretanto, conforme foi visto, a referida "ação humanitária" encontrava limites na prática, sendo que um deles foi a questão da apropriação territorial. Dessa forma, o grande papel do Estado, via DTC, foi tentar incorporar os grupos tribais à dita "sociedade moderna" e, assim, torná-los "socialmente produtivos" para que, a partir de então, eles viessem a ser - como desejavam os "positivistas gaúchos" -, respeitados enquanto seres humanos completos e não mais como crianças incapazes de se sustentar. Entretanto, essa humanidade dependia do modo como os indígenas agiam e reagiam às políticas formuladas pelo Estado e aos contatos que estabeleciam com os "ocidentais" seus vizinhos. Ou seja, quando aceitavam algumas das imposições externas que lhes eram feitas demonstravam estar no caminho da civilização e da civilidade, mas quando resistiam a elas, os termos usados para nomeá-los eram outros. Geralmente passavam a ser chamados de bugres. Palavra que no Rio Grande do Sul tem diferentes significados, sendo utilizada para qualificar o índio como bravo, bêbado, vadio, escravo etc. 


\section{FROM THE FETISHISM TO THE AGE POSITIVE: TERRITORIAL OWNERSHIP AND INDIGENOUS POLICY IN THE RIO GRANDE DO SUL OF THE FIRST REPUBLIC (1889-1925)}

Abstract: The early years of the twentieth century are marked by the presence of a concern by the government authorities in Brazil related to indigenous issues. A prime example of this was the creation, in 1910, of a federal institution responsible for dealing with indigenous issues: O Serviço de Proteção ao Índio e Localização do Trabalhador Nacional (SPILTN) - Indian Protection Service and Location of the National Worker. This attention directed at indigenous populations is also visible in Rio Grande do Sul, the state where the management of the matter was in charge of Diretoria de Terras e Colonização (DTC) - Board of Land and Colonization. In turn, in this specific case, along with the implementation of state policies aimed at the protection of indigenous, the areas traditionally inhabited by the native populations were the subject to an intense process of settlement made especially by European immigrants and their descendants. Thus, the interest of this paper is to discuss the relationship between the management of the Indian carried out by government agents and the process of land occupation that marked the region of the state forests during the First Republic.

Keywords: Indians. Land. State.

\section{Notas}

${ }^{1}$ Este artigo é uma versão atualizada de parte do capítulo 3 de minha tese de doutorado (SILVA, 2009). Nele busco aprofundar a análise de algumas questões tangencialmente pontuadas em tal capítulo, bem como realizar parte das sugestões indicadas pela banca de avaliação quando da defesa da referida tese.

${ }^{2}$ Não só, mas também o tema da República enquanto forma de governo e sua presença enquanto bandeira de luta e pauta de discussão, em momentos históricos anteriores inclusive a instalação da República no Brasil, são objetos de atenção atual. Veja-se, por exemplo, a recente publicação de um Dossiê da Revista Vária História sobre essa temática (VARIA HISTÓRIA, 2011).

3 Para conhecer mais detidamente a historiografia "mais clássica" produzida sobre a Primeira República, ver o artigo de Ângela de Castro Gomes e Marieta de Moraes Ferreira (1989).

${ }^{4}$ Periódico semestral publicado pelo Programa de Pós-Graduação em História da Universidade Federal do Rio Grande do Sul.

${ }^{5}$ Nesse sentido, destaca-se o site elaborado pelo professor John Monteiro da UNICAMP (Os índios na história do Brasil - http:/ / www.ifch.unicamp.br/ihb/), 
no qual é possível ter acesso a um grande conjunto de referências bibliográficas sobre o tema, bem como acompanhar as discussões que vêm sendo realizadas ultimamente nos Simpósios Temáticos sobre a história indígena realizados no âmbito dos encontros nacionais de história organizados pela ANPUH.

${ }^{6}$ Para acompanhar o processo de formação de novas municipalidades no Rio Grande do Sul, ver: Fundação de Economia e Estatística (1981) e Amyr Borges Fortes; et al. (1963).

${ }^{7}$ Ver as pesquisas de: Lígia Simonian (1981); Breno Antônio Sponchiado (2000); Paulo Ricardo Pezat (2003); Joel João Carini (2005); Cíntia Régia Rodrigues (2007).

${ }^{8}$ Para conhecer os processos relativos à recepção e à interpretação da teoria positivista no Brasil, ver Ângela Alonso (1996).

${ }^{9}$ Devido à questão do espaço, não aprofundarei a análise, mas existem outros motivos que levaram à decisão de deixar a organização do SPILTN sob a responsabilidade de Rondon e dos positivistas. Tais razões são detalhadamente trabalhadas por Antônio Carlos de Souza Lima no conjunto de textos de sua autoria citados ao longo deste artigo. Também é interessante conferir a tese de doutorado de Laura Antunes Maciel (1999) e os livros de Elias Bigio (2000; 2003).

${ }^{10}$ Sobre as relações entre igreja e Estado no que se refere à questão indígena no Rio Grande do Sul, especialmente sobre a atuação da Igreja Católica e da Luterana em meio aos povos nativos, verificar a tese de doutorado de Cíntia Régia Rodrigues (2007).

${ }^{11}$ Palavra recorrentemente utilizada no Rio Grande do Sul para identificar as reservas indígenas.

${ }^{12}$ Esse conjunto de relações remete a práticas muito comuns no contexto da Primeira República, as quais constituem o universo característico das relações coronelísticas (LEAL, 1997). Para aprofundar as discussões sobre a estrutura político-partidária e seu funcionamento na Primeira República, consultar o texto de Maria do Carmo Campello de Souza (1980). Em termos mais específicos sobre o caso do Rio Grande do Sul, consultar os trabalhos de Maria Auxiliadora Antonaci (1978), Celi Pinto (1979), Pedro Dutra Fonseca (1983), Loiva Otero Félix (1996), Sérgio da Costa Franco (1996), Paulo Vizentini (1998), René Gertz (2002).

\section{Referências:}

ALMEIDA, Alfredo Wagner Berno de. A ideologia da decadência: leitura antropológica a uma história da agricultura no Maranhão. Rio de Janeiro: Casa 8/Fundação Universidade do Amazonas, 2008. 
ALMEIDA, Regina Celestino. Os índios na bistória do Brasil. Rio de Janeiro: FGV, 2010.

ALONSO, Ângela. Ideias em movimento: a geração de 1870 na crise do BrasilImpério. São Paulo: Paz e Terra, 2002.

. De positivismo e de positivistas: interpretações do Positivismo Brasileiro.

In: BIB: Revista Brasileira de informações bibliográficas em Ciências Sociais, n. 42. Rio de Janeiro: Relume Dumará, 1996. p. 109-134.

ALVES, Protásio. Relatório apresentado ao Dr. Antônio Augusto Borges de Medeiros, Presidente do Estado do Rio Grande do Sul, pelo Dr. Protásio Alves, Secretário de Estado, interino, dos Negócios das Obras Públicas, em 14 de setembro de 1917. Porto Alegre: Tipografia da Empresa Gráfica Rio-Grandense, 1917.

ANTONACCI, Maria Antonieta Martines. A luta oligárquica no Rio Grande do Sul na República Velha: o movimento das oposições na conjuntura de 1921/23. São Paulo: Departamento de História da Faculdade de Filosofia, Letras e Ciências Humanas da Universidade de São Paulo, 1978. Dissertação (Mestrado).

ARDENGHI, Lurdes Grolli. Caboclos, ervateiros e coronéis: luta e resistência no norte do Rio Grande do Sul. Passo Fundo: UPF, 2003.

BIGIO, Elias. Candido Rondon: a integração nacional. Rio de Janeiro: Contraponto/ Petrobrás, 2000.

. Linhas telegráficas e integração de povos indígenas: as estratégias de Rondon (1889-1930). Brasília: FUNAI/CGDOC, 2003.

BUENO, Clodoaldo. Política externa na Primeira República. São Paulo: Paz e Terra, 2003.

CARINI, Joel João. Estado, indios e colonos: o conflito na reserva indígena de Serrinha norte do Rio Grande do Sul. Passo Fundo: Editora UPF, 2005.

CARVALHO, José Murilo. Forças Armadas e politica no Brasil. Rio de Janeiro: Jorge Zahar, 2005.

CASTRO, Celso. Os militares e a República: um estudo sobre cultura e ação política. Rio de Janeiro: Jorge Zahar, 1995.

CASTRO, Evaristo de Afonso. Notícia descritiva da região serrana na Província de São Pedro do Rio Grande do Sul compreendendo os municípios de Cruz. Alta, São Martinho, Palmeira, Passo Fundo, Santo Angelo, São Luir, Boqueirão, São Borja, São Francisco de Assis, São Vicente e Itaqui. Cruz Alta: Tipografia do Comercial, 1887.

CUNHA, Manuela Carneiro da (Org.). História dos índios no Brasil. São Paulo: Companhia das Letras: Secretaria Municipal de Cultura: FAPESP, 1992. 
DORNELLES, Soraia Sales. De Coroados a Kaigangs: as experiências vividas pelos índios num contexto de imigração no século XIX. Porto Alegre: Programa de Pós-Graduação em História da Universidade Federal do Rio Grande do Sul, 2011. Dissertação (Mestrado).

FÉLIX, Loiva Otero. Coronelismo, borgismo e cooptação política. Porto Alegre: UFRGS, 1996.

FERNANDES, Eunícia Barros Barcelos. Imagem de índios em O Malho: a imprensa como mediadora de representações. In: Texto apresentado no XXIV Simpósio Nacional de História. São Leopoldo (RS), Seminário Temático Os indios na história: fontes e problemas, 15-20 de julho de 2007.

FERREIRA, Jorge; DELGADO, Lucilia de Almeida Neves. O Brasil Republicano. Rio de Janeiro: Civilização Brasileira, 2003.

FONSECA, Pedro Dutra. RS: economia \& conflitos políticos na República Velha. Porto Alegre: Mercado Aberto, 1983.

FORTES, Amyr Borges; WAGNER, João Baptista Santiago. História administrativa, judiciária e eclesiástica do Rio Grande do Sul. Porto Alegre: Globo, 1963.

FRANCO, Sérgio da Costa. Júlio de Castilhos e sua época. Porto Alegre: UFRGS, 1996. FUNDAÇÃO DE ECONOMIA E ESTATÍSTICA (FEE). De Provincia de São Pedro a Estado do Rio Grande do Sul: Censos do Rio Grande do Sul (1803-1950). Porto Alegre: FEE, 1981.

GERTZ, René. O aviador e o carroceiro: política, etnia e religião no Rio Grande do Sul dos anos 1920. Porto Alegre: EDIPUC, 2002.

GOMES, Ângela de Castro; FERREIRA, Marieta de Moraes. Primeira República: um balanço historiográfico. In: Estudos Históricos, Rio de Janeiro, v. 2, n. 4, 1989.

GONÇALVES, Carlos Torres. Relatório da Diretoria de Terras e Colonização. In: GODOY, Candido José de. Relatório da Secretaria de Estado dos Negócios das Obras Públicas, apresentado ao Exmo. Sr. Dr. Carlos Barbosa Gonçalves, Presidente do Estado do Rio Grande do Sul, pelo Secretário de Estado, Candido José de Godoy, em 10 de setembro de 1910. Porto Alegre: Livraria do Globo, 1910.

Relatório da Diretoria de Terras e Colonização. In: GODOY, Candido José de. Relatório da Secretaria de Estado dos Negócios das Obras Públicas, apresentado ao Exmo. Sr. Dr. Carlos Barbosa Gonçalves, Presidente do Estado do Rio Grande do Sul, pelo Secretário de Estado, Candido José de Godoy, em 08 de setembro de 1911. Porto Alegre: Livraria do Globo, 1911.

Relatório da Diretoria de Terras e Colonização. In: GODOY, Candido José de. Relatório da Secretaria de Estado dos Negócios das Obras Públicas, apresentado ao 


\section{Do fetichismo à idade positiva...}

Exmo. Sr. Dr. Antônio Augusto Borges de Medeiros, Presidente do Estado do Rio Grande do Sul, pelo Secretário de Estado, João José Pereira Parobé, em 25 de agosto de 1914. Porto Alegre: Oficinas Gráficas da Livraria do Globo, 1914.

- Relatório da Diretoria de Terras e Colonização. In: PINTO, Ildefonso Soares. Relatório apresentado ao Dr. Antônio Augusto Borges de Medeiros, Presidente do Estado do Rio Grande do Sul, pelo Dr. Ildefonso Soares Pinto, Secretário de Estado dos Negócios das Obras Públicas, em 13 de agosto de 1918. Porto Alegre: Oficinas Gráficas de A Federação, 1918.

Relatório da Diretoria de Terras e Colonização. In: PINTO, Ildefonso Soares. Relatório apresentado ao Dr. Antônio Augusto Borges de Medeiros, Presidente do Estado do Rio Grande do Sul, pelo Dr. Ildefonso Soares Pinto, Secretário de Estado dos Negócios das Obras Públicas, em 16 de agosto de 1921. Porto Alegre: Oficinas Gráficas de A Federação, 1921.

GRIJÓ, Luiz Alberto. Ensino jurídico e política partidária no Brasil: a Faculdade de Direito de Porto Alegre (1900-1937). Niterói: Programa de Pós-Graduação em História da Universidade Federal Fluminense, 2005. Tese (Doutorado).

GRIJÓ, Luiz Alberto; KÜHN, Fábio; GUAZZELLI, Cesar Augusto Barcellos; NEUMANN, Eduardo Santos (Orgs.). Capitulos de bistória do Rio Grande do Sul. Porto Alegre: UFRGS, 2004.

- Origens sociais, estratégias de ascensão e recursos dos componentes da chamada geração de 1907. Porto Alegre: Programa de Pós-Graduação em Ciência Política da Universidade Federal do Rio Grande do Sul, 1998. Dissertação (Mestrado).

HOBSBAWM, Eric; RANGER, Terence. A invenção das tradições. Rio de Janeiro: Paz e Terra, 1984.

HOLANDA, Sérgio Buarque de; FAUSTO, Boris. História Geral da Civilização Brasileira. Rio de Janeiro: Bertrand Brasil, 2006.

L'ESTOLE, Benoit de; NEIBURG, Federico; SIGAUD, Lygia (Orgs.). Antropologia, Impérios e Estados Nacionais. Rio de Janeiro: Relume-Dumará, 2002.

LEAL, Victor Nunes. Coronelismo, enxada e voto: o município e o regime representativo no Brasil. Rio de Janeiro: Nova Fronteira, 1997.

LIMA, Antônio Carlos de Souza. Um grande cerco de paz: poder tutelar, indianidade e formação do Estado no Brasil. Petrópolis: Vozes, 1995.

O governo dos índios sob a gestão do SPI. In: CUNHA, Manuela Carneiro da (Org.). História dos índios no Brasil. São Paulo: Companhia das Letras: Secretaria Municipal de Cultura: FAPESP, 1992, p. 155-172. 
. O indigenismo no Brasil: migração e reapropriações de um saber administrativo. In: L'ESTOLE, Benoit de; NEIBURG, Federico; SIGAUD, Lygia (Orgs.). Antropologia, Impérios e Estados Nacionais. Rio de Janeiro: Relume-Dumará, 2002. p. 159-186.

Sobre indigenismo, autoritarismo e nacionalidade: considerações sobre a constituição do discurso e da prática da proteção fraternal no Brasil. In: FILHO, João Pacheco de Oliveira (Org.). Sociedades indígenas e indigenismo no Brasil. Rio de Janeiro: UFRJ: Editora Marco Zero, 1987.

LIMA, Nísia Trindade. Um sertão chamado Brasil: intelectuais e representação geográfica da identidade nacional. Rio de Janeiro: REVAN, IUPERJ, UCAM, 1999. MACHADO, Ironita Policarpo. Judiciário, terra e racionalidade capitalista no Rio Grande do Sul (1889-1930). Porto Alegre: Programa de Pós-Graduação em História da Pontifícia Universidade Católica do Rio Grande do Sul, 2009. Tese (Doutorado). MACIEL, Laura Antunes. Nação por um fio: caminhos, práticas e imagens da comissão Rondon. São Paulo: EDUC, 1999.

MAIA, João Marcelo Ehlert. A terra como invenção: o espaço no pensamento social brasileiro. Rio de Janeiro: Jorge Zahar, 2008.

MENDONÇA, Sônia Regina de. O ruralismo brasileiro (1888-1931). São Paulo: Editora HUCITEC, 1997.

NASCIMENTO, José Antônio Moraes. Derrubando a floresta, plantando povoados: a intervenção do poder público no processo de apropriação da terra no norte do Rio Grande do Sul. Porto Alegre: Programa de Pós-Graduação em História da Pontifícia Universidade Católica do Rio Grande do Sul, 2007. Tese (Doutorado).

NAXARA, Márcia Regina Capelari. Estrangeiro em sua própria terra: representações do brasileiro, 1870/1920. São Paulo: Annablume, 1998

OLIVEIRA, Roberto Cardoso de. O indio e o mundo dos brancos. São Paulo: UNICAMP, 1996.

PERONE-MOISÉS, Beatriz. Índios livres e índios escravos: os princípios da legislação indígena do período colonial (séculos XVI a XVIII). In: CUNHA, Manuela Carneiro da (Org.). História dos índios no Brasil. São Paulo: Companhia das Letras: Secretaria Municipal de Cultura: FAPESP, 1992, p. 115-133.

PEZAT, Paulo Ricardo. Carlos Torres Gonçalves, a familia, a pátria e a bumanidade: a recepção do positivismo por um filho espiritual de Augusto Comte e de Clotilde de Vaux no Brasil (1875-1974). Porto Alegre: Programa de Pós-Graduação em História da Universidade Federal do Rio Grande do Sul, 2003. Tese (Doutorado). 
- Augusto Comte e os fetichistas: estudo sobre as relações entre a Igreja Positivista do Brasil, o Partido Republicano Rio-Grandense e a política indigenista da República Velha. Porto Alegre: Programa de Pós-Graduação em História da Universidade Federal do Rio Grande do Sul, 1997. Dissertação (Mestrado).

PINTO, Celi Regina Jardim. Contribuição ao estudo da formação do Partido Republicano Rio-Grandense (1882-1891). Porto Alegre: Programa de Pós-Graduação em Sociologia e Ciência Política da Universidade Federal do Rio Grande do Sul, 1979. Dissertação (Mestrado).

PROCESSO CRIME $n^{\circ}$ 254. Cartório Civil Crime. Município de Palmeira das Missões, 1926. Maço 12 (Arquivo Público do Estado do Rio Grande do Sul).

RODRIGUES, Cíntia Régia. As populações nativas sob a luz da modernidade: a proteção fraterna no Rio Grande do Sul (1908-1928). São Leopoldo: Programa de Pós-Graduação em História da Universidade do Vale do Rio dos Sinos, 2007. Tese (Doutorado).

SCHWARCZ, Lilia Moritz. O espetáculo das raças: cientistas, instituições e questão racial no Brasil 1870-1930. São Paulo: Companhia das Letras, 1993.

SILVA, Marcio Antônio Both da Silva. Babel do novo mundo: povoamento e vida rural no Rio Grande do Sul da Primeira República (1889-1925). Niterói: Programa de Pós-Graduação em História da Universidade Federal Fluminense, 2009. Tese (Doutorado).

SILVEIRA, José Hemetério Velloso da. As Missões Orientais e seus antigos domínios. Porto Alegre: Companhia União de Seguros Gerais, 1979.

SIMONIAN, Ligia T. L. Terra de posseiros: um estudo sobre as políticas de terras indígenas. Rio de Janeiro: Programa de Pós-Graduação em Antropologia Social/ Museu Nacional, 1981. Dissertação (Mestrado).

- A defesa das terras indígenas: uma luta de Moysés Westphalen. Ijuí: Editora UNIJUI, 1979.

SOUZA, Maria do Carmo Campello de. O processo político-partidário na Primeira República. In: MOTA, Carlos Guilherme. Brasil em perspectiva. São Paulo/ Rio de Janeiro: DIFEL, 1980.

SPONCHIADO, Breno Antônio. O positivismo e a colonização do Norte do Rio Grande do Sul. Porto Alegre: Programa de Pós-Graduação em História da Pontifícia Universidade Católica do Rio Grande do Sul, 2000. Dissertação (Mestrado).

STÉDILE, Miguel Henrique Almeida. Da fábrica à várzea: clubes de futebol operário em Porto Alegre. Porto Alegre: Programa de Pós-Graduação em História da Universidade Federal do Rio Grande do Sul, 2011. Dissertação (Mestrado). 
TARGA, Luiz Roberto Pecoits (Org.). Breve inventário de temas do sul. Porto Alegre: UFRGS, FEE; Lajeado: UNIVATES, 1998.

TORCATO, Carlos Eduardo Martins. A repressão oficial ao jogo do bicho: uma história dos jogos de azar em Porto Alegre (1885-1917). Porto Alegre: Programa de PósGraduação em História da Universidade Federal do Rio Grande do Sul, 2011. Dissertação (Mestrado).

VARIA HISTÓRIA. Dossiê Republicanismo no Brasil do século XIX. Belo Horizonte: Departamento de História, Programa de Pós-Graduação em História, Faculdade de Filosofia e Ciências Humanas, Universidade Federal de Minas Gerais, v. 27, n. 45, jan./jun. 2011.

VIZENTINI, Paulo F. A crise dos anos 20. Porto Alegre: UFRGS, 1998.

ZARTH, Paulo. História agrária do Planalto gaúcho. Ijuí: UNIJUÍ, 1997.

Recebido em: 31/10/2012.

Aprovado em: 17/01/2012. 